\title{
Ion Exchange Isoformation for Spectrochemical Analysis with the Tape Method
}

\author{
GUSTAF SUNDKVIST*
}

The Research Laboratory of the Boliden Mining Company, Skelleftehamn, and the Department of Analytical Chemistry of the Royal Institute of Technology, Stockholm, Sweden

\begin{abstract}
A new method of treating samples to be analyzed with the tape technique is described. The sample is dissolved, and the solution is treated with cation and anion exchangers in a batch process. The dried and ground cation exchanger is spectrochemically analyzed as a powder. Different parameters of the batch process have been studied.
\end{abstract}

The tape machine, described elsewhere ${ }^{1}$, is a device to introduce the sample 1 in powder form into the spark gap. The tape machine gives a very high precision. High reproducibility on the same sample is, however, of little or no use if there are large systematical errors between different samples. The main sources of such systematical errors are variation in particle size, chemical and mineral composition.

These errors can be eliminated only by a pretreatment of the sample. For this type of pretreatment the new word "isoformation" is introduced. Different types of isoformations have been summarized previously ${ }^{2}$. The most efficient isoformation is achieved by dissolving the sample. To make it possible to use the tape technique, the solution must be converted into powder. This can be done by evaporation to dryness or by precipitation of the elements concerned. Although these methods can be used in some cases, a general method has been looked for. Isoformation by ion exchange is a result of this effort.

\section{PRINCIPLE OF ION EXCHANGE ISOFORMATION}

The sample is dissolved, and internal standard element and spectroscopic buffer are added. By a batch process the solution is separated into three components. The positive ions are attached to a cation exchanger, the negative ions to an anion exchanger, and deionized solution remains. The ion exchangers

* Boliden Mining Company, Skelleftehamn, Sweden. 
used are chosen to have different particle size and are therefore easily separated by sieving. The cation exchanger, which contains the elements to be analyzed, is dried, milled, and analyzed with the tape method. This isoformed sample is the most perfect one for the tape method since all the ions from the sample, the internal standard, and the spectroscopic buffer are mixed on almost an atomic scale.

2. DESCR IPTION OF ONE APPLICATION. ION EXCHANGE ISOFORMATION APPLIED AT THE ORE DRESSING PLANT OF BOLIDEN IN CONNECTION WITH TAPE MACHINE AND QUANTOMETER

Prior to the detailed discussion of the development of the ion exchange isoformation one case of application is described.

\subsection{Analytical situation}

At the Ore Dressing Plant of Boliden there was a need for rapid and accurate analyses. The samples are sulphides of $\mathrm{Zn}, \mathrm{Cu}, \mathrm{Pb}, \mathrm{As}$, and $\mathrm{Fe}$, or mixtures of these and rocks in any proportions. The analytical program covers contents up to $60 \%$ and down to hundredths of a per cent. The elements to be determined are $\mathrm{Zn}, \mathrm{Cu}, \mathrm{Pb}$, and $\mathrm{Fe}$, and in some cases $\mathrm{Bi}$. There are essentially three factors that have contributed to the solution of this analytical problem: ion exchange isoformation, tape machine, and direct reading spectrograph. The tape machine was previously developed, and the direct reading spectrograph used, the Quantometer, is commercially available.

\subsection{Procedure}

2.2.1. Weighing and solution of samples. $200 \mathrm{mg}$ of the sample are weighed within $\pm 0.1 \mathrm{mg}$ and transferred to a $400 \mathrm{ml}$ beaker. The amount of sample corresponds to a max. of 5 milliequivalents (mequiv). The sample is dissolved in $4 \pm 0.5 \mathrm{ml}$ diluted perchloric acid (70\% acid diluted 1:1) on a hot plate. Infrared lamps are used for additional heat. The acid is added from a "whipping flask". Ábout one minute is required for solution. Most of the acid is evaporated to near, but not complete, dryness. It is desired to evaporate as much free acid as possible, while still avoiding the formation of insoluble oxides.

2.2.2. Ion exchange. The walls of the beaker are washed with $10-20 \mathrm{ml}$ deionized water. $15.00 \mathrm{ml}$ internal standard solution containing $10.00 \mathrm{~g} \mathrm{Cd} / \mathrm{l} \mathrm{as}$ perchlorate are added from a Dettker automatic pipette. This corresponds to 2.68 mequiv. The accuracy of the pipette is better than $0.1 \%$.

12.00 mequiv of Dowex $50 \mathrm{~W}, \mathrm{X}-12,200-400$ mesh cation exchanger in hydrogen form are added, and the solution is diluted with deionized water to about $150 \mathrm{ml}$. The solution with ion exchanger is heated to near boiling. The amount of cation exchanger which corresponds to 12.00 mequiv is determined by titration. The amount may vary depending on residual contents of water and acetone but is normally about $3.3 \mathrm{~g}$. 
After some minutes $5.0 \mathrm{ml}$ of $0.60 \mathrm{~N} \mathrm{~K}_{2} \mathrm{CO}_{3}$-solution, i.e. 3.0 mequiv, are added with automatic pipette. As the solution is strongly acidic, there is no risk of precipitation of metal hydroxides. Potassium is used as spectroscopic buffer.

In order to take care of the acid and displace the equilibrium, $20 \mathrm{~g}$ of anion exchanger are added. In this way the cation exchanger can take up the positive metal ions quantitatively. The anion exchanger used is Amberlite IR-45, 20-50 mesh, which is a weak base resin. The amount corresponds to about 60 mequiv, which is a rather large excess. The excess is necessary to displace the equilibrium sufficiently and to make the reaction proceed rapidly. The amount of anion exchanger is not critical, and the addition can be performed by using volume measurement. The ion exchange is complete when $\mathrm{pH}$ is 3.0-3.5. This can be checked with a $\mathrm{pH}$ paper. The procedure of ion exchange, after the addition of the anion exchanger, takes about $5 \mathrm{~min}$. This time is of course dependent on the capacity of the anion exchanger and upon the completeness of the acid fuming mentioned above.

2.2.3. Separation and drying of cation exchanger. The separation of the cation exchanger is performed at the so-called "ion exchange table" (Ref.", Fig. 3, p. 128) *. Use is made of specially designed plastic funnels connected to a vacuum. The funnels consist of two parts - the upper part contains a 60 mesh screen of stainless steel, the lower part contains a supporting screen. Three filter papers (OB Munktell) are placed on the supporting screen and kept in position by a plastic ring. In performing the separation the upper part of the funnel is connected to the lower part. The content of the beaker is washed into the upper part. The separation is performed by a shower of deionized water (pressure $1.2 \mathrm{~kg} / \mathrm{cm}^{2}$ ). The cation exchanger passes down to the filter paper, and the anion exchanger remains on the screen in the upper part. After the separation the upper part is removed and the anion exchanger is washed down to a container. The "ion exchange table" at Boliden has twelve funnels.

The drying of the cation exchanger is done by two treatments with acetone. Each time $10 \pm 1 \mathrm{ml}$ of acetone are added from a "whipping flask", and a contact time of $1 \mathrm{~min}$ is allowed before the acetone is removed by suction. After the second treatment with acetone, air is drawn through the cation exchanger for $3 \mathrm{~min}$. Since the cation exchanger and the filter papers are now dry, the cation exchanger is easily removed from the filter paper almost quantitatively. Small losses of cation exchangers can be tolerated, as every grain contains internal standard, buffering element, and elements to be analyzed, in the same proportions.

2.2.4. Grinding of the cation exchanger. The ion exchanger must be ground to be used with the tape technique. The grinding should be performed as soon as possible so that the samples, which are not in equilibrium with the content of water in the atmosphere, do not change their composition. The grinding is performed in the swingmill manufactured by Messrs. Siebtechnik, Mühlheim (Ruhr) [Ref.2, Fig. 1, p. 128]. The mill grinds 6 samples simultaneously for $6 \mathrm{~min}$. The milling can, of course, be performed in mills having only one millhouse and in that case the milling time can be reduced. The millhouse and mill-

* Figs. 2 and 3 in Ref. ${ }^{2}$ happened to be interchanged.

Acta Chem. Scand. 15 (1961) No. 7 
bodies are made from Avesta $739 \mathrm{~S}$ stainless steel. As the efficiency of the mill is dependent on the amount of material to be milled, the entire sample should be transferred to the mill. If the ground sample is to be stored it should be kept in a tight plastic box. The houses and bodies are cleaned by washing with water. They are wiped absolutely dry with towels or paper.

2.2.5. Excitation, analysis, and calculation. The isoformed samples are analyzed with an ARL Quantometer and a tape machine. The excitation is accomplished with an ARL High Precision Source Unit modified to give 50 sparks per second.

The lines used are summarized in Table 1. The Cd line 2288 is strongly self reversal, but can be used as an analytical line up to about $1 \% \mathrm{Cd}$. It is mainly used for checking the self absorption conditions in the spark ${ }^{3}$. The intensity of this Cd line is used as a parameter for correcting other self reversal lines. Calcium gives a specific contribution to the background underneath the $\mathrm{Zn}$ line 3345. $20 \% \mathrm{CaO}$ corresponds to $0.07 \% \mathrm{Zn}$. The Ca line $3179 \times 2$ can be used as correction parameter.

Table 1. Spectral lines.

\begin{tabular}{|c|c|c|}
\hline Element & $\operatorname{Lin} \theta$ & Ranges \\
\hline $\begin{array}{l}\mathrm{Cd} \\
\mathrm{Zn} \\
\Rightarrow \\
\mathrm{Pb} \\
\mathrm{Cu} \\
\mathrm{Cu} \\
\mathrm{Bi} \\
\mathrm{Ca} \\
\text { Background }\end{array}$ & 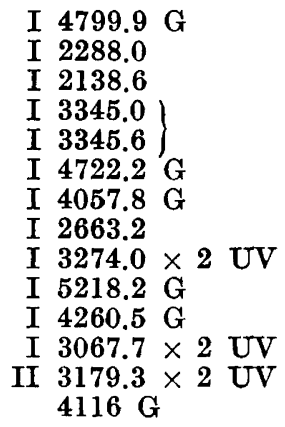 & $\begin{array}{l}\text { Internal standard } \\
0-1 \% \mathrm{Cd} \\
0-0.7 \% \mathrm{Zn} \\
0-3,3-15 \% \mathrm{Zn} \\
15-60 \% \mathrm{Zn} \\
0-3,3-15 \% \mathrm{~Pb} \\
15-60 \% \mathrm{~Pb} \\
0-0.5,0.5-2.5 \% \mathrm{Cu} \\
2-10,10-30 \% \mathrm{Cu} \\
0-50 \% \mathrm{Fe} \\
0-1 \% \mathrm{Bi} \\
0-20 \% \mathrm{CaO}\end{array}$ \\
\hline
\end{tabular}

$\mathrm{G}=$ glass filter, UV $=$ UV.filter

At low levels of $\mathrm{Pb}, \mathrm{Zn}$, and $\mathrm{Fe}$ a higher precision is obtained, if a correction is made for variations in the general background. These variations are due mainly to variation in running times. The background measured at $4116 \AA$ is the parameter for this correction.

Tabulated fixed working curves are used and are the same for all types of products. The values obtained are corrected against standard samples, which have been treated in the same way as the samples. This must be done as a small curve drift cannot be avoided. The corrections are based on the values obtained for a low and a high standard on the same curve.

2.2.6. Standard samples made from solutions. The standard samples are made from weakly acidic perchlorate solutions. The contents have been chosen so that $15.00 \mathrm{ml}$ standard solution corresponds to $200.0 \mathrm{mg}$ sample. Table 2 
shows the composition of the five standard solutions which are necessary and are sufficient for a complete check of all analytical lines for $\mathrm{Zn}, \mathrm{Pb}, \mathrm{Cu}$, and Fe. The contents given in Table 2 are not the actual ones in the solution but are the contents of the corresponding $200 \mathrm{mg}$ sample.

Table 2. Standard samples.

\begin{tabular}{|c|r|r|r|r|c|}
\hline Notation & $\% \mathrm{Zn}$ & $\% \mathrm{~Pb}$ & $\% \mathrm{Cu}$ & $\% \mathrm{Fe}$ & $\% \mathrm{Bi}^{*}$ \\
\hline $\mathrm{A}$ & 58.00 & 2.00 & 0.50 & 0.00 & - \\
$\mathrm{B}$ & 12.00 & 60.00 & 0.00 & 10.00 & $\overline{-}$ \\
$\mathrm{C}$ & 2.00 & 12.00 & 22.00 & 20.00 & $(0.50)$ \\
$\mathrm{D}$ & 0.50 & 0.00 & 2.00 & 46.00 & $(1 . \overline{0})$ \\
\hline
\end{tabular}

* For Bi a freshly prepared solution should be added separately.

2.2.7. Preparation of internal standard solution. The internal standard solution is prepared in lots of 60 liters by dissolving $\mathrm{CdO}$ or $\mathrm{CdCO}_{3}$ in perchloric acid. The contents are determined and adjusted by titration with EDTA.

2.2.8. Purifying and drying of cation exchanger. Since the cation exchanger Dowex 50 contains some impurities, for example $\mathrm{Fe}$, it has to be purified before use. Further, it must be dried in order to weigh out a definite amount to each sample. Treatment is as follows:

a) The cation exchanger is purified by treatment with $2 \mathrm{~N} \mathrm{HCl}$ and oxalic acid in a batch process.

b) If the cation exchanger is Dowex $50 \mathrm{~W}$ instead of Dowex 50 , it should be treated with an alluviation in water of extremely finely ground Dowex 2 in OH-form $(0.025 \%$ of the amount of cation exchanger). Without this treatment Dowex $50 \mathrm{~W}$ shows a strong "electrostatic effect".

c) The ion exchanger is dried by treatment with acetone and by suction of air through the exchanger.

d) The ion exchanger is treated in a mixer in order to make it homogeneous with respect to the residual contents of acetone and water.

The capacity of the dried cation exchanger, which is about 3.6 mequiv per gram, is determined by titration in the following way: $1 \mathrm{~g}$ of ion exchanger is treated with $40 \mathrm{ml}$ of warm $0.1 \mathrm{~N} \mathrm{NaOH}$ for $10 \mathrm{~min}$. After filtration the solution (and the wash water) is back-titrated with $0.1 \mathrm{~N} \mathrm{H}_{2} \mathrm{SO}_{4}$ using methyl red as indicator.

2.2.9. Regeneration of anion exchanger. In this particular case there are economic reasons to use the anion exchanger over and over again. It has therefore to be purified and regenerated. The purification and regeneration is performed in a 60 liters plastic jar which contains two bottoms, the upper one being a 50 mesh stainless screen. The jar has a draining tap, which can be connected to the vacuum line via a large suction bottle. The treatment is performed in the following steps: 
a) Treatment with neutral 0.03 M EDTA solution. After a time of contact of $30 \mathrm{~min}$ the solution is removed by suction as completely as possible.

b) Washing with deionized water. Time of contact is $15 \mathrm{~min}$.

c) Treatment with neutral $0.03 \mathrm{M} \mathrm{Ca}\left(\mathrm{ClO}_{4}\right)_{2}$ solution to remove the surplus of EDTA.

d) Washing as above (b).

e) Regeneration with $4 \mathrm{~N} \mathrm{NH}_{3}$. The time of contact should be at least $12 \mathrm{~b}$.

f) Washing with deionized water until the wash solution is neutral.

g) After the last washing the anion exchanger is dried by drawing air through it.

The capacity of the anion exchanger is determined in the following way: $1 \mathrm{~g}$ of anion exchanger is treated at $100^{\circ} \mathrm{C}$ with 10 mequiv acid in $100 \mathrm{ml} \mathrm{H}_{2} \mathrm{O}$. After filtration the solution is back-titrated with $\mathrm{NaOH}$. The capacity should not be much less than 3 mequiv/g.

2.3. Risks of contaminations at ion exchange isoformation. Since products with widely different concentration ranges are ion exchanged, ground and run at the same time, close attention must be paid to the risk of mutual contamination. The relative effect of contamination is, of course, increased due to the very large dilution of the sample with ion exchanger. Many of these risks can be eliminated by carefulness by the operator; in other cases certain steps have to be taken.

2.3.1. Funnels and millhouses. The mills and the screens of the funnels must be stainless. Screens of brass would, of course, contaminate the samples with $\mathrm{Cu}$ and $\mathrm{Zn}$. A usual chrome steel mill cannot be used since the elements more noble than the material of the mill will be precipitated on the mill surfaces. Even when using screens and mills of stainless steel, samples of widely different composition should be treated in different funnels and different millhouses. If a high level sample of $\mathrm{Cu}, \mathrm{Pb}$ or $\mathrm{Zn}$ is milled, the next sample will be contaminated up to about $0.03 \%$.

2.3.2. Water and reagents. The reagents used and the ion exchangers shall be as pure as possible with respect to the elements to be analyzed. This holds especially for the water and the anion exchanger, where the amount as well as the impurity level may vary. Distilled water from brass apparatus is not pure enough and should be purified. A suitable method is to have the distilled water pass through a filter of cation exchanger which is in hydrogen form.

2.4. Hazards with ion exchange isoformation. Attention must be paid to possible risks when working with perchloric acid. Solution and ion exchange must be performed in different hoods. Dilution with internal standard solution and water shall be performed before the beaker is moved to the second hood. The hood, where the solution is performed, must not contain any wood or other organic material.

The ground ion exchanger, which contains poisonous metals, is very finely divided. Therefore, good ventilation is necessary where the millhouses are emptied.

As acetone is used attention must be paid to the risk of fire. 


\section{DEVELOPMENT OF THE ION EXCHANGE ISOFORMATION}

\subsection{Column versus batch process}

The ion exchange isoformation differs from conventional analytical application of ion exchange 4,5 . The ion exchange resin must contain the ions to be analyzed with the tape technique in a homogeneous mixture. Although it might be possible to obtain a homogeneous resin by milling, the column still has some serious drawbacks. If a column process is used the cation exchanger must be quantitatively recovered. To make such a recovery without losses is very difficult. The present batch process is much more rapid than the column process both in the time of reaction and the time used for recovery of the ion exchanger. As the cation exchanger is completely homogeneous, small losses can be tolerated in connection with separation, drying, and grinding. The drawback of the batch process compared to the column process is that the cations are not completely taken up by using only a cation exchange resin. However, since quantitative recovery is possible if the equilibrium is displaced by using cation and anion exchangers simultaneously, the batch process has been chosen.

\subsection{Choice of cation exchanger}

3.2.1. Weak and strong cation exchangers. A cation exchanger containing the strongly acidic sulphonic acid group is completely dissociated and acts as cation exchanger at all $\mathrm{pH}$ levels with constant capacity of exchange. For a cation exchanger with weakly acidic groups the ion exchange equilibrium is coupled to a protolysis equilibrium. Such an ion exchanger does function only in neutral or alkaline solution.

A weak cation exchanger is unsuitable since no exchange occurs until the anion exchanger has taken up or eliminated the excess acid of the solution. Besides the fact that the ion exchange takes a long time, this means, losses of cations.

The possibility of obtaining Dowex 50 in hydrogen form and in different particle sizes and with different crosslinkings has significantly influenced the choice of this cation exchanger. The strongly acidic cation exchangers have good thermal stability and can stand $100^{\circ} \mathrm{C}$ even in acidic solutions.

3.2.2. Choise of grain size and crosslinking. The grain size has been chosen to be 200-400 mesh for reasons which shall be mentioned later in connection with the choice of anion exchanger. The crosslinking is not critical. Too high a crosslinking (X-16, $16 \%$ divinyl benzene) makes the reaction slower. Too low a crosslinking ( $\mathrm{X}-4,4 \%$ divinyl benzene) makes drying with acetone more difficult. X-12 with $12 \%$ crosslinking has been chosen without any special investigation. $\mathrm{X}-8$ is presumably equally well suited.

\subsection{Cation exchange}

3.3.1. Equilibrium and affinities of the cation exchange. In treating, for example, a cation exchanger in hydrogen form with a solution containing metallic ions, an equilibrium is established between the positive ions of the solution and those of the ion exchanger.

Acta Chem. Scand. 15 (1961) No. 7 


$$
\underbrace{\mathrm{R} \cdot \mathrm{SO}_{3}^{-} \mathrm{H}^{+}}+\mathrm{Me}^{\mathrm{n}+} / \mathrm{n} \rightleftharpoons \underbrace{\mathrm{R} \cdot \mathrm{SO}_{3}^{-} \mathrm{Me}^{\mathrm{n}} / \mathrm{n}}+\mathrm{H}^{+}
$$

where $\mathrm{Me}^{\mathrm{n}+}$ are the metal ions. Although the different types of cation exchangers have different affinities for different cations the equilibrium is never quantitatively displaced in one or the other direction.

3.3.2. Displacement of the equilibrium by dilution. The ion exchange equilibrium is a Donnan equilibrium.

Using concentrations an equilibrium constant $K_{\mathrm{H}^{+}}^{\mathrm{Me}^{\mathrm{n}+}}$ can be defined in the following way. $R$ refers to the ion exchange phase and $S$ to the water phase

$$
\frac{\left[\mathrm{Me}^{\mathrm{n}+}\right]_{\mathrm{R}}}{\left[\mathrm{H}^{+}\right]_{\mathrm{R}}^{\mathrm{n}}}=\frac{\left[\mathrm{Me}^{\mathrm{n}+}\right]_{\mathrm{S}}}{\left[\mathrm{H}^{+}\right]_{\mathrm{S}}^{\mathrm{n}}} \times K_{\mathrm{H}^{+}}^{\mathrm{Me}^{\mathrm{n}+}}
$$

This formula shows that multivalent ions are more efficiently taken up at a higher dilution.

Investigations have been performed that show that an uptake above $90 \%$ of multivalent ions can be obtained by using only cation exchanger, if the dissolved sample is fumed to near dryness and the capacity of the ion exchanger is not utilized to more than $50 \%$.

Although the dilution technique could be used in some cases, especially at low concentrations where a rather large relative error up to $10 \%$ could be tolerated, it is not a satisfactory procedure in most instances. First of all this technique could not be used for monovalent ions. Furthermore, according to the formula (2) the amount of uptake of a certain ion varies with the following parameters: excess acid in the solution, excess capacity of the ion exchanger, and chemical composition of the sample.

3.3.3. Displacement of the equilibrium by removal of hydrogen ions. The equilibrium (1) is displaced completely to the right, if the hydrogen ions or other corresponding ions originally in the cation exchanger are removed from the equilibrium in some way. General methods can be based only on the use of cation exchangers in hydrogen form. The following more or less special methods can be used.

a) The equilibrium is automatically displaced if the sample is or can be transformed to salts (oxides, hydroxides, carbonates) of weak uncharged acids (water, carbonic acid). An example of such a technique is the use of $\mathrm{K}_{2} \mathrm{CO}_{3}$ solution for the addition of spectroscopic buffer.

$$
2 \mathrm{R} \cdot \mathrm{SO}_{3}{ }^{-} \mathrm{H}^{+}+2 \mathrm{~K}^{+}+\mathrm{CO}_{3}{ }^{2-} \rightarrow 2 \mathrm{R} \cdot \mathrm{SO}_{3}-\mathrm{K}^{+}+\mathrm{H}_{2} \mathrm{O}+\mathrm{CO}_{2}
$$

b) Neutralization with an anion base and similtaneous precipitation of its counter cation as a very insoluble salt of the anion of the sample. For ion exchange of a sample containing no other anions than $\mathrm{SO}_{4}{ }^{2-}$ it might be possible to titrate with $\mathrm{Ba}(\mathrm{OH})_{2}$ to a point where all sulphuric acid is precipitated as $\mathrm{BaSO}_{4}$.

c) Neutralization with an anion base or neutral base whose corresponding cation or formed cation acid cannot react in the cation exchange due to its size. 
The cases (a) and (b) are special ones and very difficult to perform. A precipitation of metal carbonates is often incomplete and a filtration is necessary. A titration as in case (b) is also tedious. The case (c) has made possible a more general method by using strongly or weakly basic anion exchangers. The hydroxyl form or carbonate form of a strong anion exchanger contains the anion bases $\mathrm{OH}^{-}$and $\mathrm{CO}_{3}{ }^{2-}$, respectively, whose corresponding cations are fixed in the carbon skeleton of the anion exchanger. The cations formed by protolysis of the uncharged amino groups of a weak anion exchanger are also firmly bound. The advantages of this method of equilibrium displacement is that it is universal and simple. The amount of added anion exchanger is not critical. With a surplus of anion exchanger the outer solution can, at the most, become neutral and never alkaline, and therefore hydroxides and basic salts normally are not precipitated.

\subsection{Complete deionization of the solution by using both cation and anion exchangers}

3.4.1. The displacement of the equilibrium using strongly or weakly basic anion exchangers. A strongly basic anion exchanger contains positively charged quaternary ammonium groups in a network polymer. Furthermore, it contains displaceable negative ions as, for example, chloride ions. It is completely dissociated at all pH levels and acts therefore as an ion exchanger in both acidic and basic environments. It can bind anions of both strong and weak acids. When used to deionize solutions, a strong anion exchanger should be in hydroxyl or carbonate form. $\mathrm{CO}_{3}{ }^{2-}$ and $\mathrm{OH}^{-}$combine with $\mathrm{H}^{+}$forming volatile $\mathrm{CO}_{2}$ and $\mathrm{H}_{2} \mathrm{O}$ respectively. The equilibrium (1) is therefore quantitatively displaced to the right.

In the case of weak anion exchangers, a protolysis equilibrium exists together with the ion exchange equilibrium. The ion exchanger in the base form contains free amino groups, which can bind hydrogen ions by protolysis. Electroneutrality is obtained through the fact that the acid anion is bound as counter ion. Accordingly, a weak anion exchanger acts as an acid uptaker when deionizing solutions:

$$
\mathrm{R} \cdot \mathrm{NH}_{2}+\mathrm{H}^{+}+\mathrm{ClO}_{4}^{-} \rightleftharpoons \underbrace{\mathrm{R} \cdot \mathrm{NH}_{3}+\mathrm{ClO}_{4}^{-}}
$$

The equilibrium is strongly displaced to the right in acidic solutions (up to $\mathrm{pH} 3-4)$.

3.4.2. Choice of anion exchanger. Weak versus strong anion exchangers. As the ion exchange is performed in acidic or neutral solutions, there are no principal reasons for choosing one or the other type. The choice of IR-45 in the Boliden application is mainly due to practical and economic considerations. As will be shown later, a strong anion exchanger should be preferred when analyzing monovalent cations.

The following anion exchangers have been investigated: Amberlite IR-4B, IR-45, and IRA-400, and Dowex 2 . When choosing a suitable anion exchanger, the following factors have to be considered: losses in the final solution, losses in form of complexes on the anion exchanger, losses as precipitates, ease of

Acta Chem. Scand. 15 (1961) No. 7 
regeneration, thermal and mechanical stability, capacity, speed, electrostatic properties, and shape of grains. None of the above mentioned anion exchangers have optimum properties in all these respects and the choice is therefore a question of the best compromise.

The losses during ion exchange are discussed in detail later on. Here a summary is given of the considerations that have influenced the choice of anion exchanger in this special case. When analyzing only multivalent ions, as in the Boliden program, it is possible to reduce the losses to a negligible level when using a weak as well as a strong anion exchanger.

In the particular application described above the anion exchanger has for economic reasons to be regenerated and used several times. In respect of regeneration the weak anion exchanger has an advantage since it loses its ion exchange property due to protolysis in an alkaline solution and therefore completely gives off the acid. The regeneration can, in this case, be performed with ammonia. The equilibrium of regeneration of a strong anion exchanger is not equally strongly displaced and this type of anion exchanger is therefore more difficult to regenerate. Also the costs of chemicals are greater.

The thermal stability is different for different anion exchangers. The weak anion exchanger IR-45 has the best thermal stability and can stand $100^{\circ} \mathrm{C}$ without noticeable loss of capacity. Dowex 2 and Amberlite IRA-400 in $\mathrm{OH}^{-}-$ forms cannot stand temperatures higher than $40^{\circ} \mathrm{C}$ and $60^{\circ} \mathrm{C}$ respectively, but at those temperatures they are almost as rapid as IR-45 at $100^{\circ} \mathrm{C}$. The fact that it in practice is much easier to maintain a working temperature of $100^{\circ} \mathrm{C}$ than 40 or $60^{\circ} \mathrm{C}$ makes the use of IR-45 more attractive. According to our experience it has also shown very good mechanical stability. Because of the round form of the grains, IR-45 is easily sieved. A drawback of Amberlite IRA-400 compared to Dowex 2 and IR-45 is that this anion exchanger has a strong electrostatic affinity to the cation exchanger Dowex 50, which makes the separation more difficult.

Since the losses at the ion exchange can be kept within tolerable limits, the choice of IR-45 for the actual analytical programs is based mainly on the practical considerations discussed above.

3.4.3. Some considerations on the time required for the ion exchange. Choice of a mixed bed performance. When ion exchange isoformation is to be used for routine analysis it has to be as rapid as possible. If the anion exchanger is kept separate within a fabric container the time for ion exchange will require several hours.

This time can be reduced to about 5 min using a mixed bed performance. The cation and anion exchangers must then be separated after the ion exchange for the following reasons:

a) If the analysis is performed on a mixture of cation and anion exchanger the sensitivity is greatly reduced.

b) The matrix of the sample will not be defined, since the amount of acid varies.

c) The anion exchanger can be used several times.

The most convenient method of separation of the exchangers is sieving and therefore the exchangers must have different grain sizes. A coarse anion exchanger and a fine cation exchanger have been chosen in order to facilitate 
the recovery and regeneration of the anion exchanger. The performance of sieving and drying becomes more practical when the anion exchanger remains on the screen. Undissolved gangs which are finely divided follow the cation exchanger and do not contaminate the anion exchanger.

The anion exchanger has been chosen with grain sizes 20-50 mesh, the cation exchanger 200-400 mesh. The sieving is performed with a 60 mesh stainless screen.

In addition to the influence of the preciously mentioned conditions, the speed of the ion exchange is influenced by the following factors: temperature, stirring, dilution, and amount of anion exchanger. The temperature should be as high as the stability of the exchanger allows, which means that the ion exchange should be performed at $100^{\circ} \mathrm{C}$ when IR-45 is used. While boiling, a certain amount of stirring also results. A small volume and a large amount of anion exchanger increase the speed but also increase the loss of ions.

The ion exchange can be interrupted at $\mathrm{pH} 3-3.5$ (checked with a $\mathrm{pH}$ paper).

3.4.4. The degree of utilization of the cation exchanger. The capacity of the cation exchanger shall be utilized to as high a degree as is possible with regard to the consequences of the equilibrium equation (2) for a quantitative ion exchange (3.5.) and with regard to the maximum content of milliequivalents in the sample. To keep the cost low the amount of cation exchanger should be as small as possible. A limit however, is set by the fact that the weighed sample has to be large enough to cancel out possible nonhomogeneities of the sample and to allow sufficiently accurate weighing. It is not possible to take aliquots in the presence of precipitates as, for instance, $\mathrm{PbSO}_{4}$. In the Boliden program it is considered most practical to have a constant amount of sample, $200 \mathrm{mg}$, for all types of samples and a constant amount of cation exchanger corresponding to 12.00 mequiv. Including internal standard and buffer, the capacity of the ion exchanger is utilized up to between 80 and $90 \%$, the charges on the metal ions being assumed to be the same as their valency.

This is not valid under all circumstances. For multivalent ions a higher value of the nonutilized capacity than the one theoretically expected is obtained by titration. The explanation might be that the water molecules, which coordinate around these ions split off hydrogen ions to a certain degree. Thus, the water complexes of the metal ions have a lower charge and consequently occupy fewer sites in the exchanger.

Moreover, the situation is probably that the redistribution of the charges on the ions does not occur before almost all hydrogen ions have disappeared from the cation exchanger, which is not the case at $\mathrm{pH} 3.5$ according to the equilibrium (2). A good measure of the nonutilized capacity is obtained in the following way: The cation exchanger from the ion exchange is titrated with $\mathrm{KOH}$ by successive additions of, for example, 0.1 mequiv. After each addition a few grains of the cation exchanger are taken out of the reaction vessel and placed on a filter paper. I drop of neutral $\mathrm{Ca}\left(\mathrm{ClO}_{4}\right)_{2}$ solution containing a suitable amount of methyl orange is added. Hydrogen ions are liberated at the test only by ion exchange between $\mathrm{Ca}^{2+}$ ions and possibly remaining $\mathrm{H}^{+}$ions. A relatively sharp color change is generally obtained (the red color does not appear), when all hydrogen ions are titrated. When the cation exchanger

Acta Chem. Scand. 15 (1961) No. 7 
contains much iron the point of change is, however, not sharp. The ion exchanger is obviously buffered by the system $\mathrm{Fe}(\mathrm{OH})^{2+} \mathrm{aq} \rightleftharpoons \mathrm{Fe}(\mathrm{OH})_{2}^{+} \mathrm{aq}+\mathrm{H}^{+}$. Estimating the average charges on the $\mathrm{Fe}$ ions at +1.4 and using the normal charges for $\mathrm{Zn}, \mathrm{Cu}, \mathrm{Pb}, \mathrm{Cd}$, and $\mathrm{K}$, a very good agreement is obtained between titrated and calculated values.

3.5. Sources of error during ion exchange. In a perfect isoformation by ion exchange all the metal ions should be $100 \%$ on the cation exchanger. However, losses outside the resins in the form of precipitates and on the anion exchanger in the form of complexes or hydrolyzed products contribute to inaccuracy of the analysis. The losses due to complexes are the most severe. In general, it is possible to reduce them to a negligible level by taking certain steps. Furthermore, it should be remembered that it is the variation in losses that contributes to the errors and therefore the conditions of the ion exchange from sample to sample should be kept as constant as possible.

3.5.1. Losses in the solution. Such losses can be due to the following factors: Insufficient capacity of the cation exchanger, noncharged soluble complexes, too low final $\mathrm{pH}$.

After the separation of the ion exchangers it is possible to check that the capacity of the cation exchanger has been sufficient by placing a few grains of the cation exchanger on a $\mathrm{pH}$ paper wetted with a $\mathrm{Ca}\left(\mathrm{ClO}_{4}\right)_{2}$ solution. The paper shall indicate a strongly acidic reaction as the $\mathrm{Ca}^{2+}$ ions displace the excess hydrogen ions.

Noncharged complexes can, of course, occur in the solution at the beginning, but they are, in general, dissociated rapidly due to the displacement of the equilibrium.

Losses due to the final $\mathrm{pH}$ being too low are, of course, largest for monovalent ions. Assuming equation (2) valid, the relative loss of ions due to incomplete deionization of the solution is

$$
F=\frac{10^{-n} \cdot \mathrm{pH} \cdot v}{K \cdot E(1-x)^{n}}
$$

where $F=$ loss

$v=$ volume of water phase

$E=$ total capacity of cation exchanger in milliequivalents

$x=$ the degree of utilization of the cation exchanger

$y=$ the part of the total capacity occupied by the monovalent metal ion

$K=$ selectivity constant in relation to the hydrogen ion

The parameters which affect the losses in the solution are as follows: volume of solution in relation to amount of cation exchanger $(v / E)$, degree of utilization $x$, valence $n$, factor of selectivity $K$, and $\mathrm{pH}$ of the solution.

According to (5) the value of $(v / E)$ should be as low as possible. As total losses must be considered and as the losses on the anion exchanger increase when the volume decreases, there is an optimum value for the volume, the other conditions being constant and the kinetics disregarded for the moment. It should be remembered that the effect of dilution is different when only cation exchanger is used and when cation exchanger is used in combination with a 
weak anion exchanger. A weak anion exchanger constitutes a buffer system and therefore the $\mathrm{pH}$ of the solution is almost independent of the dilution. When a weak anion exchanger is present, the losses in the solution increase with dilution. On the other hand, these losses decrease for a multivalent ion when no anion exchanger is present.

The losses in the solution are strongly dependent upon the degree of utilization when $x$ approaches 1 . The losses of a monovalent ion increase 10 times when $x$ increases form 0 to 0.9 and of a divalent ion $10^{2}$ times. From the point of view of the spectrochemical sensitivity $x$ should be as high as possible. When $x$ is 0.8 there is, however, not very much more to be gained in this respect.

The losses in the solution are influenced exponentially by the valence $n$ and the $\mathrm{pH}$ of the solution. If the hydrogen ion concentration is decreased, for instance, 100 times, the concentration of another monovalent ion is decreased to the same extent but of a divalent ion $100^{2}$ times. Using a strong anion exchanger the end $\mathrm{pH}$ obtained is close to the neutral point and a complete deionization is therefore obtained even for monovalent ions. When using weak anion exchangers as IR-45 the end $\mathrm{pH}$ will be 3.5, if the total amount of anions in the solution to be deionized corresponds to $30 \%$ of the original capacity of the ion exchanger. Using a weak anion exchanger the end $\mathrm{pH}$ is dependent on the ratio, base form/acid form, in conformity with the formula for a solution buffer system:

$$
\mathrm{pH}=\mathrm{p} K_{\mathrm{s}}+\log \frac{[\text { base }]}{[\text { acid }]}
$$

From this formula it is obvious that the anion exchanger ought to be as completely regenerated as possible. Furthermore, an excessive amount should be used so that the base form predominates, even when the ion exchange is finished.

The losses in the solution can be neglected in the case of multivalent ions. The choice of suitable solution volume during ion exchange is therefore in this case determined primarily by the losses on the anion exchanger and by the kinetics of the reaction. By choosing suitable conditions, it is possible to keep the solution losses of monovalent ions, too, at a sufficiently low level, even when a weak anion exchanger is used. This is especially true for Ag, which has a factor of selectivity of 18. In this case, however, other complications prevent the use of a weak anion exchanger.

3.5.2. Losses in form of precipitates which are not dissolved by the ion exchangers. This is a problem only for the few monovalent ions $\left(\mathrm{Ag}^{+}, \mathrm{BiO}^{+}\right)$that form insoluble precipitates. Precipitates of multivalent ions are relatively easily dissolved by the ion exchangers. The combination strong cation exchanger strong anion exchanger is the most efficient one.

The important factors when considering losses in form of precipitates are end $\mathrm{pH}$, the degrees of utilization of cation and anion exchangers, valence, and, of course, solubility product. Kinetics also play a most important role.

Insoluble precipitates might occur originally in the solution or be formed during the ion exchange. Examples of the first case are lead sulphate and silver chloride, which can be formed when dissolving sulphides. Examples of the

Acta Chem. Scand. 15 (1961) No. 7 
second case are the basic salts, which can be precipitated as well within the anion exchanger as in the solution. This latter case has been observed with bismuth.

If the anion exchanger contains chloride ions, which often is the case with a strong anion exchanger which is delivered in the chloride form and is very difficult to purify from residual chloride ions, then $\mathrm{AgCl}$ is precipitated within the anion exchanger and the precipitate cannot be dissolved in a reasonably short time. When a weak anion exchanger is used losses of the same type can occur on account of chloride ions in the solution or in the anion exchanger. It is, however, difficult to study these losses in the case of a weak anion exchanger since other types of losses more predominant occur at the same time.

Precipitates of $\mathrm{PbSO}_{4}$ are no problem. The amounts of $\mathrm{Bi}$ to be determined at Boliden are less than $0.50 \%$ in the samples corresponding to less than $1 \mathrm{mg}$ in the cation exchanger. At these concentrations there are no difficulties, since the total losses in the solution and in form of $\mathrm{BiOClO}_{4}$ are less than 2 per cent of the amount present.

If the amount of $\mathrm{Bi}$ is larger than around $60 \mathrm{mg}, \mathrm{BiOClO}_{4}$ is precipitated when adding the anion exchanger.

3.5.3. Losses in form of complexes on the anion exchanger. The losses on the anion exchanger can be of the following types:

1) Losses due to precipitations. This has already been treated in 3.5.2.

2) Losses due to cations complexed directly to the active centers within the anion exchanger.

3) Losses due to negatively charged complex ions, which are bound in the same way as other anions.

Losses of the second type occur only on a weak anion exchanger and are due to the property of the amino group of complexing a positive metal ion in conformity with its ability to complex the hydrogen ion, i.e. to be protolyzed.

$$
\begin{aligned}
& \mathrm{RNH}_{2}+\mathrm{H}^{+} \rightleftharpoons \mathrm{RNH}_{3}{ }^{+} \\
& \mathrm{RNH}_{2}+\mathrm{Ag}^{+} \rightleftharpoons \mathrm{RNH}_{2} \mathrm{Ag}^{+}
\end{aligned}
$$

By complex binding, the $\mathrm{N}$-atom utilizes its ability to form a fourth electron pair bond with help of its free electron pair. On a strong anion exchanger, on the other hand, the $\mathrm{N}$-atom is already bound to four other atoms by molecule bonds, and therefore the $\mathrm{N}$-atom cannot act as a donor of electron pairs binding positive metal or hydrogen ions. The magnitude of the losses due to complexes directly on the anion exchanger can be expected to depend on the following factors: the valence, the magnitude of the stability constant of the complex, the degree $x$ of utilization of the cation exchanger, the $\mathrm{pH}$ of the solution according to (2), the amount of anion exchanger (number of milliequivalents), and the ratio (acid/base) of the anion exchanger. Some of these factors are dependent on each other to some extent.

In addition to the above mentioned factors, the kinetics certainly play a role. The kinetics are influenced by the volume, the way of adding the anion exchanger, and the relative speeds of the exchangers. The number of multivalent ions present in the solution when adding the anion exchanger is depen- 
dent on the volume of the solution and therefore the volume affects the kinetics. Furthermore, losses of multivalent ions are smaller if the anion exchanger is added in several portions. This is due to the square influence of the hydrogen ion concentration according to (2), the smaller amount of the base form in the first portion of added anion exchanger, and the irreversibility of the binding of metal ions to the amino groups. That such an irreversibility exists is obvious from the fact that the cation exchanger is not contaminated, when using an anion exchanger containing considerable amounts of such complexes. When such an anion exchanger is used, the amount of anion exchanger should, however, be added in one portion. At an excess of acid there is a protolysis even of the amino groups to which the metal ions are bound, resulting in elutriation of the metal ions. A third kinetic factor is the speed of the cation exchanger versus the speed of the anion exchanger. The cation exchanger is much more rapid than the anion exchanger, as it should be. Also, the cation exchanger is added before the anion exchanger.

Losses of the third type, i.e. in the form of negative complex ions may occur on a weak anion exchanger as well as on a strong one, but seem to occur to a larger extent in the latter case.

Besides the properties of the type of anion exchanger used and the factors influencing the first type of complex losses, there is essentially one additional factor affecting the losses due to negative complex ions. The concentration of the complex-forming anion in the solution and in the anion exchanger is of very large importance.

Complex ions can be assumed to be taken up on the anion exchanger in two different ways. Complex ions already in the solution are taken up by the anion exchanger or complex ions are formed within the anion exchanger due to combination of positive metal ions with anions already present in the anion exchanger. The losses in the two cases are

$$
\begin{aligned}
& f_{1}=k_{1} \cdot C_{\mathrm{Me}^{n+}} \cdot C_{\mathrm{A}^{-}(\mathrm{S})}^{m} \cdot \mathrm{M}_{\mathrm{A}} \\
& f_{2}=k_{2} \cdot C_{\mathrm{Me}^{n+}} \cdot C_{\mathrm{A}^{-}(\mathrm{R})}^{m} \cdot \mathrm{M}_{\mathrm{A}}
\end{aligned}
$$

$\mathrm{MeA}_{m}^{(m-n)-}$ is the composition of the complex, $C_{\mathrm{A}^{-}(\mathrm{S})}$ is the concentration of the anion in the water phase, $C_{\mathrm{A}^{-}(\mathrm{R})}$ is the concentration in the anion exchanger, and $\mathrm{M}_{\mathrm{A}}$ is the amount of anion exchanger.

If $n>1$ then $C_{\mathrm{Me}^{n}}+$ is strongly dependent on $\mathrm{pH}$ and accordingly on the volume of the solution, when adding the anion exchanger. The same is valid for $C_{\mathrm{A}^{-}(\mathrm{s})}$ and even to a greater extent for $C_{\mathrm{A}^{-}(\mathrm{S})}^{m}$. By addition of the anion exchanger in several portions, the hydrogen concentration is reduced in steps. In this way the total losses can be diminished substantially.

The influence of the above mentioned factors is shown in Tables 3 and 4, which summarize some of the investigations made. All the investigations in Table 3 have been performed by solution and ion exchange of the same sample $(22 \% \mathrm{Cu}, 14 \% \mathrm{Zn}, 23 \% \mathrm{Fe}, 5000 \mathrm{ppm} \mathrm{Ag})$. Deviations from the normal procedure are indicated in the table. $5+15$ indicates that $5 \mathrm{~g}$ of anion exchanger have been added first and the rest after $5 \mathrm{~min}$ at $100^{\circ} \mathrm{C}$. Dowex 2 was originally

Acta Chem. Scand. 15 (1961) No. 7 
in the chloride form, but it has been partially converted to the carbonate form by regeneration with $2 \mathrm{~N} \mathrm{Na}_{2} \mathrm{CO}_{3}$ solution. In the investigations reported in Table 4, the ion exchange was performed on pure perchlorate, chloride, and nitrate solutions of the ions concerned (10 mequiv). Internal standard and buffer have not been added in this case. Except for this, the ion exchange was performed in the usual way.

The losses have in all cases been determined by elutriation of the anion exchanger with $150 \mathrm{ml} 1 \mathrm{~N} \mathrm{HClO}_{4}$, fuming of the acid, and repeated ion exchange.

Table 3. Ion exchange of $\mathrm{Cu}$ concentrates under different conditions. $x \sim 0.75$. Losses on the anion exchanger.

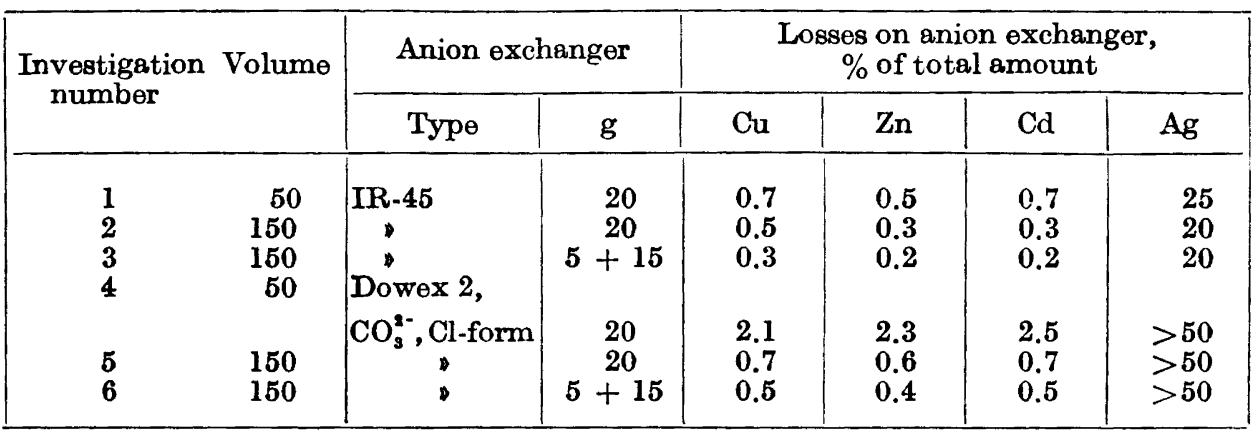

Table 4. Ion exchange of pure solutions of $\mathrm{Cu}, \mathrm{Pb}, \mathrm{Zn}$ and $\mathrm{Cd}$ in the form of chlorides, perchlorates, and nitrates. $x=0.85$. Losses on the anion exchanger (IR-45).

\begin{tabular}{|c|c|c|c|c|c|}
\hline \multirow{2}{*}{$\begin{array}{c}\text { Investigation } \\
\text { number }\end{array}$} & Acid & \multicolumn{3}{|c|}{ Losses on anion exchanger, \% of total amount } \\
\cline { 2 - 6 } & $\mathrm{Cu}$ & $\mathrm{Zn}$ & $\mathrm{Pb}$ & $\mathrm{Cd}$ \\
\hline $1-4$ & $\mathrm{HCl}$ & 1.8 & 1.9 & 0.15 & 1.4 \\
$5-8$ & $\mathrm{HClO}_{4}$ & 1.7 & 1.3 & 0.15 & 0.5 \\
$9-12$ & $\mathrm{HNO}_{3}$ & 2.0 & 1.0 & 0.15 & 0.4 \\
\hline
\end{tabular}

The results show that, at the conditions chosen, there are great difficulties with silver, but that the losses of the other ions are small. The final error of the analysis is dependent on the variation in these losses, which is still smaller. Table 4 indicates also that the losses in form of negative complex ions are relatively unimportant on a weak anion exchanger, the difference between different counter ions being comparatively small. The larger losses reported in Table 4, compared to those in Table 3 are explained by the fact that $(1-x)^{2}$ is about 3 times less. 
In the following a summary is given of the steps that should be taken in order to reduce the total losses on the anion exchanger:

a) The anions of the solution should have as small a tendency as possible to complex the metal ions. This is especially important when using a strong anion exchanger. The perchlorate ion is best in this respect.

b) The anion exchanger shall not contain complex-forming anions as, for instance, chloride ions to any great extent. In conformity with (a) this holds especially for a strong anion exchanger.

Although, complex-forming anions cannot be completely avoided, the losses can often be reduced to a negligible level in the following ways:

c) The volume of the solution should be as large as possible. The limit is indicated by the increased time of ion exchange.

d) The anion exchanger can be added in several portions. When an impure weak anion exchanger is used, attention should be paid to possible elutriation of metal ions during the first step.

c) The degree of utilization of the cation exchanger can be reduced. This is the most efficient of the last three factors. By a relatively small sacrifice of spectrochemical sensitivity it is possible to reduce the losses to the order of $0.1 \%$.

3.6. Choice of procedure of solution. When applying the described isoformation method the sample always has to be dissolved by acids, an alkaline fusion technique introducing excessive amounts of alkali ions. In the Boliden Ore Dressing Plant application, solution with perchloric acid has been chosen mainly for the following reasons.

a) The solution is rapid (ready in $2 \mathrm{~min}$ ).

b) The perchlorate ions do not complex the metal ions.

c) The formation of free sulphur is avoided. Free sulphur is known to give losses due to inclusions.

d) An essential part of the sulphur content vanishes as gaseous sulphur chlorides ${ }^{6}$. As not all sulphur is transferred to sulphate, the lead ions have a larger solubility. Table 5 shows the amount for different types of products. Solution and fuming were performed in a $400 \mathrm{ml}$ beaker.

Table 5. Formation of sulphate when dissolving sulphide products.

\begin{tabular}{|c|c|c|c|c|}
\hline \multirow{2}{*}{\multicolumn{2}{|c|}{ Product }} & \multirow{2}{*}{ Acid } & \multicolumn{2}{|c|}{ Amount of sulphate obtained } \\
\hline & & & $\mathrm{mg}$ & $\begin{array}{c}\% \text { of theoretical } \\
\text { amount }\end{array}$ \\
\hline $\begin{array}{l}\mathrm{Zn} \text { concentrate, } \\
\mathrm{Cu} \text { concentrate, } \\
\mathrm{Pb} \text { concentrate, } \\
\mathrm{FeS}_{2} \text { concentrate, }\end{array}$ & $\begin{array}{l}200 \mathrm{mg} \\
200 \mathrm{mg} \\
200 \mathrm{mg} \\
200 \mathrm{mg} \\
200 \mathrm{~N} \\
200\end{array}$ & $\begin{array}{c}4 \mathrm{ml} \mathrm{HClO}_{4}(1: 1) \\
" \\
" ~ \\
2 \mathrm{ml} \mathrm{HClO}_{4}(70 \%) \\
\mathrm{Br}_{2}+3 \mathrm{ml} \mathrm{HNO}_{3} \text { (conc.) }\end{array}$ & $\begin{array}{r}9 \\
13 \\
6 \\
35 \\
50 \\
300\end{array}$ & $\begin{array}{r}5 \\
6 \\
4 \\
12 \\
17 \\
100\end{array}$ \\
\hline
\end{tabular}


Free sulphur is obtained when dissolving with aqua regia. The formation of free sulphur can be avoided by dissolving with $\mathrm{Br}_{2}$ (wetting of the sample) and nitric acid. This solution procedure is inconvenient and furthermore the sulphide is quantitatively converted to sulphate as seen in Table 5. The most convenient solution is obtained with perchloric acid (70\% acid, diluted 1:1).

The recommended use of $\mathrm{HClO}_{4}$ does not exclude the use of other common acids such as $\mathrm{HCl}, \mathrm{HNO}_{3}, \mathrm{HF}$, or $\mathrm{H}_{2} \mathrm{SO}_{4}$. However, at least when using a strong anion exchanger it is advantageous to fume with perchloric acid after dissolving with one of the volatile acids. If it is necessary to have a complexforming anion to keep the metal ion in solution a weak anion exchanger should be used, possibly added in portions, and the cation exchanger should be utilized to less than $50 \%$.

3.7. Drying and milling of the cation exchanger. Prior to the analysis with the tape method the cation exchanger has to be dried and milled. The drying cannot be performed with heat as the cation exchanger is not stable and metallic oxides will be formed on its surfaces. It is performed with acetone and by drawing air through the exchanger. The air humidity should be relatively constant and preferably not to high. When drying is done in this way the milling has to be performed in inert mills. It should be remembered that the cation exchanger, even when dried, acts as an electrolyte. Therefore, the noble metals as, for instance, $\mathrm{Cu}$ are precipitated on the surfaces of a $\mathrm{Cr} 13$ steel mill in agreement with the electromotive force series.

Our experience has shown that mill house and bodies of Avesta $739 \mathrm{~S}$ steel is the best compromise between nobility and hardness. This steel contains molybdenum. That this steel is sufficiently noble is demonstrated by the fact that even $\mathrm{Ag}$ is not precipitated.

When using Cr 13 steel mills, the amount of precipitated $\mathrm{Cu}$ varies and may reach several per cent of the amount present. By a rather complicated procedure of drying it is, however, possible to avoid these losses of $\mathrm{Cu}$ when milling in a $\mathrm{Cr} 13$ steel mill. In principle, this is done by neutralizing the residual hydrogen ions of the cation exchanger with a $\mathrm{C}_{2} \mathrm{H}_{5} \mathrm{OH}-\mathrm{NH}_{3}$ mixture after removing most of the water.

The more noble molybdenum steel is, however, definitely to be recommended when the samples contain noble metals because of the much simpler procedure of drying. A hard chrome-plated mill would probably be the best solution.

The time of milling is not critical but should be kept constant.

3.8. Spectroscopic buffer. At the Boliden Ore Dressing Plant application, an inner buffer has been chosen, which means that the buffering element is added to the solution and sticks to the cation exchanger in the same way as the elements to be analyzed and the internal standard. Having a high equivalent weight and a low ionization potential potassium has been chosen as buffering element. It is also possible to use an outer buffering substance added at the milling. In this case the buffering element will not utilize any of the capacity of the cation exchanger. The only compounds containing alkali which can be used as outer buffer are the feldspars, since the ions of the buffering substance must be strongly bound so that no ion exchange can occur at the milling. This alternative procedure of buffering has been rejected for two 
reasons. In the first place it is very difficult to obtain a pure feldspar. Most of the natural feldspars contain, among other things, lead. Secondly, there will be too great wear on the mills made of $739 \mathrm{~S}$ steel.

3.9. Pretreatment of the cation exchanger. With regard to the purifying, drying, and titration of the cation exchanger before its use there is nothing to be added to the description of the procedure.

When using Dowex $50 \mathrm{~W}$ a surface treatment of the cation exchanger must be performed. Dowex $50 \mathrm{~W}$ is less fluid than Dowex 50 after the drying with acetone and sticks together making it difficult to weigh and mix. It has been observed that Dowex $50 \mathrm{~W}$ obtains the same fine properties as Dowex 50, if not better, by treatment with an alluviation in water of a very small amount of extremely finely ground anion exchanger in base form.

The sticky property of the resin grains is due to hydrogen bonds. The difference between Dowex $50 \mathrm{~W}$ and Dowex 50 must be that the latter has much fewer sulphonic acid groups on the surface. The substitution of metal ions for hydrogen ions occurs homogeneously throughout the whole grain. The anion exchanger on the other hand cannot penetrate the cation exchanger and neutralizes therefore only the sulphonic acid groups on the surface.

3.10. Regeneration and purifying of the anion exchanger. The purifying and regeneration of the weak anion exchanger IR-45 is described in 2.2.9. This treatment is of course done especially to conform to that analytical program.

The impurities are partly in the form of cation exchanger containing metal ions, partly in the form of complexes on the anion exchanger. It can never be taken for granted that the separation of the cation and the anion exchanger is completely accomplished. Therefore, to avoid contamination, the metal ions must be removed from the cation exchanger. The metal ions, which are held on the anion exchanger as complexes do not interfere if they are not elutriated under the conditions used at the ion exchange. It is possible to purify the anion exchanger completely by treatment with a surplus of acid. The cost of chemicals will, however, in this case be relatively high due to the large amount of acid used and due to the about four times larger amount of $\mathrm{NH}_{3}$ required for the regeneration since the anion exchanger after the acid treatment is completely in its acid form. For the above reasons, the acid treatment has been excluded as a procedure for purifying in this application.

The most efficient way of removing the cations from a cation exchanger is to treat the exchanger with an agent which forms strong complexes with the metal ions. Since the stability constants of the metal complexes of EDTA are of such magnitude that EDTA can be used for titration of metal ions, it can be expected that this complexing agent should be very efficient even when not used in a large excess. $\mathrm{Cu}, \mathrm{Zn}, \mathrm{Pb}$, and $\mathrm{Cd}$ are the most important elements to be removed. $\mathrm{Cu}, \mathrm{Zn}$, and $\mathrm{Pb}$ have to be determined at high as well as low levels and from a practical point of view it is inconvenient to keep the anion exchangers which are used at different levels separated. Iron is to be determined only at relatively high content and the demand for accuracy is less. In any case, the accuracy of the Fe determination is limited by the fact that a steel mill is used. 
In the investigation reported in Table $6150 \mathrm{mg}$ cation exchanger $(200-400$ mesh) containing metal ions was mixed with $100 \mathrm{~g}$ pure anion exchanger $(20-50$ mesh). The mixture was treated with EDTA solution after which the cation and anion exchangers were separated by sieving and the cation exchanger analyzed spectrochemically.

Table 6. Purifying of the anion exchanger IR-45.

\begin{tabular}{|c|c|c|c|c|c|c|c|}
\hline \multirow{2}{*}{$\begin{array}{l}\text { Investigation } \\
\text { number }\end{array}$} & \multirow{2}{*}{ Treatment } & \multirow{2}{*}{$\begin{array}{l}\text { Time } \\
\text { min. }\end{array}$} & \multicolumn{5}{|c|}{ Relative amounts } \\
\hline & & & $\mathrm{Cu}$ & $\mathrm{Zn}$ & $\mathrm{Cd}$ & $\mathrm{Pb}$ & $\mathrm{Fe}$ \\
\hline $\begin{array}{c}\text { Untreated ca- } \\
\text { tion exchanger } \\
1 \\
2 \\
3\end{array}$ & $\begin{array}{l}100 \mathrm{ml} 0.03 \mathrm{M} \text { EDTA } \\
100 \mathrm{ml} \mathrm{0.03} \mathrm{M} \text { EDTA }\end{array}$ & $\begin{array}{r}5 \\
25\end{array}$ & $\begin{array}{r}100 \\
1 \\
<1\end{array}$ & $\begin{array}{r}100 \\
1 \\
<1\end{array}$ & $\begin{array}{r}100 \\
1 \\
<1\end{array}$ & $\begin{array}{r}100 \\
1 \\
<1\end{array}$ & $\begin{array}{r}100 \\
50 \\
50\end{array}$ \\
\hline & $+2 \mathrm{ml}$ conc. $\mathrm{NH}_{3}$ & 25 & $<1$ & $<1$ & $<1$ & 50 & 50 \\
\hline
\end{tabular}

Obviously it is not possible to remove the lead ions from the cation exchanger by simultaneously stripping with EDTA and regenerating the anion exchanger with ammonia. The treatments have to be performed in different steps. The treatment with EDTA is performed in neutral solution and the surplus of EDTA is complexed by adding a neutral $\mathrm{Ca}\left(\mathrm{ClO}_{4}\right)_{2}$ solution.

It has been observed that only part $(\sim 30 \%)$ of the metal ions bound to the amino groups of the anion exchanger are removed by this procedure of purifying and regeneration. This degree of elutriation is, however, sufficient to keep the content of metal ions in the anion exchanger within tolerable limits. Investigations have shown that these metal ions are not stripped off during the ion exchange if an excess of anion exchanger is added. As the concentrates are only a small part of the whole analytical program the risks of contamination are small even when the anion exchangers are mixed.

\section{DISCUSSION OF RESULTS OBTAINED}

When estimating the overall accuracy of the method, random as well as systematic errors must be considered. Errors at the ion exchange process, the excitation, and the recording should be included. The first of these sources of errors has already been discussed in detail, and the errors have been shown to be very small at the conditions chosen.

Disregarding the errors at the solution of the samples it is possible to test the method with respect to precision as well as accuracy with the use of synthetic solutions. The ion exchange isoformation method is therefore independent of chemical analyses of reference samples, which is not the case with conventional spectrochemical methods. Dissolving with perchloric acid the errors 
associated with the solution procedure are small as no free sulphur is formed which might contain inclusions. Further, the losses due to volatilization are negligible, which has been checked by repeated fuming.

The precision obtained at different levels is shown in an earlier paper (Ref. ${ }^{3}$, Table 1).

The systematic errors are of two types, absolute errors due to influence from coincidences or specific backgrounds, and relative errors due to variation in relative sensitivities. The first type of error has been reduced to a large extent by using the most sensitive spectral lines as analytical lines at the lower concentration ranges. The small errors of this type, which might remain, can be corrected in a satisfactory way. Although these sensitive lines are strongly self absorbing, they can be used successfully because of the great dilution of the sample.

In this application the relative errors are very small, and it is found possible to use only one working curve for each analytical line independent of the matrix. Some results are presented in an earlier paper (Ref. ${ }^{2}$, Tables 1, 2).

\section{OTHER APPLICATIONS OF ION EXCHANGE ISOFORMATION}

Although the investigation described above was made primarily with respect to a special analytical program, the method has, of course, many other applications. It can be used for all the elements, that form positive ions and have suitable spectral lines.

Ion exchange isoformation can be applied to the following elements: $\mathrm{Li}$, $\mathrm{Na}, \mathrm{K}, \mathrm{Rb}, \mathrm{Cs}, \mathrm{Cu}, \mathrm{Ag}, \mathrm{Be}, \mathrm{Mg}, \mathrm{Ca}, \mathrm{Sr}, \mathrm{Ba}, \mathrm{Zn}, \mathrm{Cd}, \mathrm{Hg}, \mathrm{Al}, \mathrm{Sc}, \mathrm{Y}, \mathrm{La}, \mathrm{Ga}$, In $\mathrm{Tl}$, rare earths (if the sensitivity is sufficient), $\mathrm{Sn}$ (II), $\mathrm{Pb}, \mathrm{Sb}$ (III), $\mathrm{Bi}, \mathrm{Cr}, \mathrm{Mn}$, $\mathrm{Fe}, \mathrm{Co}$, and $\mathrm{Ni}$. In the case of all these elements, the losses at the ion exchange can be reduced to the order of $0.1 \%$. To this group of elements uranium and thorium can be added. They are taken up to the same extent but do not have sensitive lines. Vanadium(V) goes to the cation exchanger after reduction, for example, with ascorbic acid. The losses might be somewhat larger in this case (around $1 \%$ ).

In the case of all the elements mentioned above except $\mathrm{Ag}$, a weak anion exchanger can be used. For Ag a strong anion exchanger, substantially free from chloride ions, is necessary.

The alkali metal ions suffer no complex losses on the anion exchanger. The losses in the solution are negligible when using a strong anion exchanger, but even in the case of a weak anion exchanger these losses are easily reduced below $1 \%$.

The alkaline earth metal ions are the most ideal ones, the losses in as well solution as anion exchanger being negligible at all conditions.

$\mathrm{Fe}, \mathrm{Cr}$, and the third group metals (especially $\mathrm{Al}$ ) can be lost in the anion exchanger in the form of negatively charged hydroxo complexes or uncharged precipitates.

Attention must be paid to the fact that the commercially available ion exchangers often contain $\mathrm{Al}, \mathrm{Ca}$, and $\mathrm{Mg}$ and have to be purified. 
In the case of $\mathrm{Sn}$ (II) and $\mathrm{Sb}$ (III) a complex-forming counter ion is required to keep the metal ions in solution, and a weak anion exchanger is therefore definitely to be preferred.

For the rest of the ions mentioned above it is in principle possible to use either a weak anion exchanger or a strong one.

In this general field of application attention should be paid to some interelement effects. In most cases they can be reduced to a negligible level by choice of suitable internal standard elements.

The ion exchange isoformation method has its universal range of application as a pretreatment method for the tape technique. In special cases, however, it can be used also in X-ray fluorescence. In this case a complete isoformation is achieved with respect to particle size and structure. It is not possible to eliminate the influence from the matrix by referring to only one internal standard. Furthermore, the sensitivity is in general too low.

Acknowledgements. The author in indebted to Dr. Axel Johansson (Assoc. Professor of the Department of Analytical Chemistry of the Royal Institute of Technology, Stockholm) and to Dr. Allan Danielsson (The Boliden Mining Company, Skelleftehamn) for valuable discussions. The author thanks the Management of the Boliden Mining Company for permission to publish this paper.

\section{REFERENCES}

1. Danielsson, A., Lundgren, F. and Sundkvist, G. Spectrochim. Acta 15 (1959) 122.

2. Danielsson, A. and Sundkvist, G. Spectrochim. Acta 15 (1959) 126.

3. Danielsson, A. and Sundkvist, G. Spectrochim. Acta 15 (1959) 134.

4. Kitchener, J. A. Ion-Exchange Resins, John Wiley \& Sons. Inc. New York 1957.

5. Samuelsson, O. Ion-Exchangers in Analytical Chemistry, John Wiley \& Sons Inc. New York 1952

6. Smith, G. F. Analyst 80 (1955) 16.

Received March 6, 1961. 